\title{
Cardiólogo encuentra un caso de enfermedad de Fabry
}

\author{
Cardiologist finds a case with Fabry disease \\ Javier D. Ramírez-Grisales ${ }^{1 *}$ y María V. Ortega-López² \\ ${ }^{1}$ Servicio de Cardiología; 2 Servicio de Medicina General, Consulta externa. Fundación Clínica Shaio, Bogotá, Colombia
}

\section{Resumen}

En este reporte se llama la atención de los colegas ante la posibilidad de encontrar un caso de enfermedad de Fabry entre múltiples pacientes que consultan. Se exponen las condiciones clínicas de estos pacientes que los hacen únicos, a causa de una enfermedad huérfana. Es posible que muchas de estas condiciones clínicas hayan pasado inadvertidas y al no tenerlas presentes no se tenga un grado de sospecha que lleve al diagnóstico.

Palabras clave: Enfermedad de Fabry. Enfermedad huérfana. Sospecha diagnóstica.

\begin{abstract}
In this report is call the attention of our colleagues the possibility of finding a case of Fabry's disease within the multitude of patients in our practice. It is expose the clinical conditions of these patients which make them unique, due to a disease denominated as orphan. It is possible that many of these clinical conditions have gone unnoticed and by not having them present prevent/impide us from having a high degree of suspicion which would lead to a diagnosis.
\end{abstract}

Key words: Fabry disease. Orphan disease. Diagnostic suspicion.

\section{Introducción}

La enfermedad de Fabry es un tipo de enfermedad de depósito lisosómico, hereditaria, ligada al cromosoma $X$, que lleva a mutaciones del gen para la enzima alfa galactosidasa, formando parte del grupo de las mucopolisacaridosis. Fue descrita por Johannes Fabry y William Anderson a finales del siglo xix.

Se estima que afecta 1 de cada 40.000 a 60.000 varones recién nacidos. En mujeres se desconoce su prevalencia.

El defecto de la alfa galactosidasa hace que se acumule globotriosilceramida (GL-3) en los lisosomas, produciéndose acumulación del metabolito $y$, por consiguiente, afección sistémica de distintos órganos.

Por tanto, la acumulación del GL-3 en pequeños vasos, nefronas, nervios, miocardiocitos, etc., dará lugar a diferentes manifestaciones sistémicas y compromiso orgánico.

Para el tratamiento de esta entidad se dispone de una sustitución enzimática al reponer la enzima alfa agalsidasa deficitaria y prevenir así la acumulación del GL-3. En consecuencia, se puede afirmar que no se trata de una cura; se requiere el uso endovenoso de la enzima cada dos semanas por tiempo indefinido,

\section{Correspondencia:}

*Javier D. Ramírez-Grisales

E-mail: javier.ramirez@shaio.org
Disponible en internet: 10-06-2021 Rev Colomb Cardiol. 2021;28(2):171-174 www.rccardiologia.com 0120-5633 @ 2020 Sociedad Colombiana de Cardiología y Cirugía Cardiovascular. Publicado por Permanyer. Este es un artículo open access bajo la licencia CC BY-NC-ND (http://creativecommons.org/licenses/by-nc-nd/4.0/). 
pero es posible detener la progresión de la enfermedad, mejorar y mantener la calidad de vida e impedir el avance a la disfunción de los órganos vitales, con la consecuente morbilidad y mortalidad que acarrea ${ }^{1,2}$.

\section{Caso}

Paciente remitido con una serie de estudios previos y tratamiento formulado por el servicio de Nefrología, quien ingresó a una valoración por Cardiología previa a trasplante renal.

Paciente de sexo masculino, de 39 años, hispanoamericano, soltero, natural de Salamina Caldas, procedente y residente de Bogotá, operario de plásticos hasta mayo de 2018, católico practicante, con grado de escolaridad bachillerato completo, vacante, quien se hallaba en proceso de trasplante renal, en hemodiálisis tres veces a la semana. La etiología de la falla renal no era clara, pero se atribuía al uso de antiinflamatorios no esteroides, que el paciente consumía para alivios de dolores múltiples y en algunas ocasiones originados de una presunta artrosis. Entre los paraclínicos enviados a cardiología aportó el informe de un ecocardiograma transtorácico con fracción de eyección ventricular izquierda del 65\%, dilatación de cavidades derechas y aurícula izquierda. GRP (grosor relativo de pared) del ventrículo izquierdo de 0.66 para un valor normal de 0.42 y un índice de masa ventricular izquierdo de 200 gramos $/ \mathrm{m}^{2}$, para un valor normal en hombres de hasta 115, correspondiente a severa hipertrofia concéntrica del ventrículo no obstructiva en reposo, sin zonas de hipoquinesia con signos de disfunción diastólica tipo II e insuficiencia mitral leve. La función ventricular derecha estaba conservada, el septum interauricular era de tipo aneurismático; por lo demás, pudo considerarse normal. Infortunadamente, no fue posible obtener las imágenes porque el paciente no permitió el acceso a las mismas y la EPS no autorizó realizar un ecocardiograma institucional. El electrocardiograma fue interpretado como hipertrofia del ventrículo izquierdo.

El interrogatorio de este paciente se dificultaba un poco porque se aquejaba de hipoacusia y, además, por momentos, tenía problemas para aportar datos relevantes de su historia clínica; era excesivamente concreto y tenía escasa capacidad para hacer abstracciones y verbalizarlas.

En sus antecedentes se encontró un dato de hipertensión arterial, pero no pudo establecerse el inicio de la misma; sin embargo, sí parecía coincidir el inicio de hemodiálisis 7 meses atrás. Tenía un hermano mayor

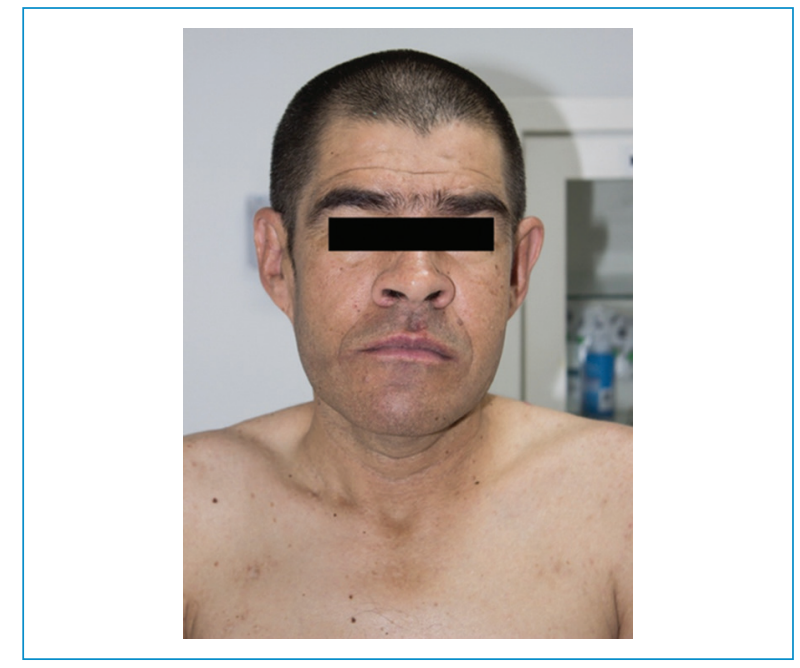

Figura 1. Arcos supraorbitarios prominentes, cejas tupidas y puente nasal ancho.

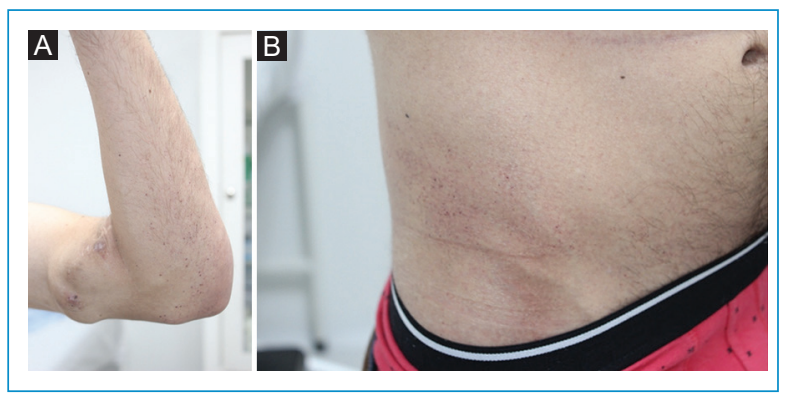

Figura 2. Pápulas de color violáceo con borde definido, no levantadas y algunas de ellas cubiertas por hiperqueratosis. A: en codo. B: fosa ilíaca.

con diagnóstico de 'esquizofrenia', quien estaba al cuidado de su progenitora. En su comportamiento psicosocial de definía como 'rebelde', con déficit académico; durante tres años cursó primero de bachillerato, y su actividad básica consistía en ver televisión o visitar a sus tíos, no tenía hijos ni se le conocía pareja.

Al examen físico se encontró paciente usuario de anteojos, 50 kilogramos, talla $1.70 \mathrm{~cm}$, tensión arterial 100/80 mm Hg, frecuencia cardiaca 72 latidos por minuto, arcos supraorbitarios prominentes, cejas tupidas y puente nasal ancho (Fig. 1). En codo y fosas ilíacas se encontraron múltiples pápulas de color violáceo, con borde definido, no levantadas, algunas de ellas cubiertas por hiperqueratosis (Fig. 2).

El dato inicial que llamó la atención en este caso fue una hipertrofia ventricular izquierda severa en un 


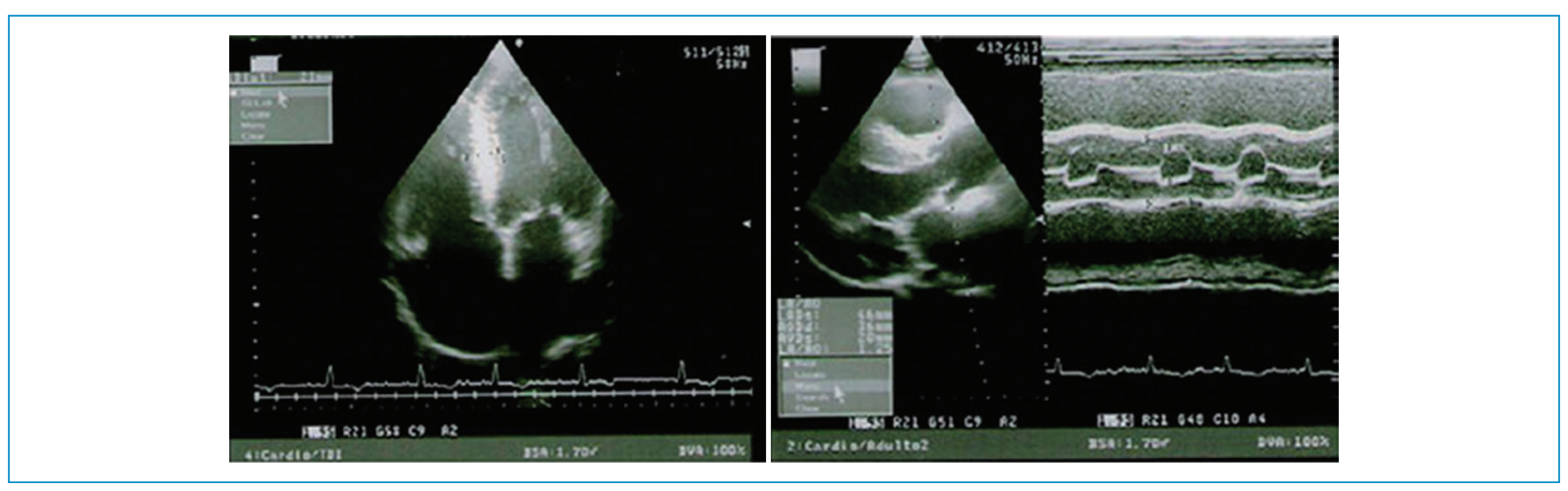

Figura 3. Ecocardiograma ilustrativo de HVI, con septum de $21 \mathrm{~mm}$ en un paciente con enfermedad de Fabry.

paciente joven (Fig. 3), sin hipertensión arterial de larga data, que justificara este hallazgo y enfermedad renal crónica de etiología no clara atribuida a AINE utilizados para manejo de múltiples dolores. En el examen físico se evidenciaron angioqueratomas y dificultades del interrogatorio a causa de hipoacusia, lo cual elevó la sospecha diagnóstica para enfermedad de Fabry. Se solicitó alfa-galactosidasa A (GSSPF) en gota de sangre en papel de filtro y en leucocitos, y se obtuvieron los siguientes resultados: $0.7 \mathrm{nmol} / \mathrm{ml} / \mathrm{hora}$ con control normal de 2.0 a 21.8 en papel de filtro y en leucocitos $0.70 \mathrm{nmol} / \mathrm{mg} \mathrm{prot} / \mathrm{h}$ con valor normal de $20-100$. El análisis genético molecular por secuenciación encontró la variante c.298AT en estado homocigoto clasificada como patogénica, llegando de esta manera al diagnóstico conclusivo de enfermedad de Fabry variante clásica. Se inició tratamiento con agalsidasa beta a dosis de $1 \mathrm{mg} / \mathrm{kilogramo} /$ peso, intravenosa, cada 2 semanas, valoración por oftalmología en búsqueda de córnea verticilata, seguimiento por cardiología ante la posibilidad de desarrollar arritmias y falla cardiaca, y seguimiento por nefrología para continuar hemodiálisis y su camino hacia trasplante renal que, por supuesto, no será el de un donante familiar.

Se notificó al paciente y a su acompañante para iniciar pesquisa de casos sintomáticos o no en su núcleo familiar.

\section{Discusión}

Como se expresó antes, la enfermedad de Fabry tiene manifestaciones multisistémicas y es común que el diagnóstico sea tardío cuando no exista un antecedente familiar que sensibilice el inicio de la búsqueda.
Por ello, un gran número de casos son diagnosticados por el servicio de Nefrología y cuando esto ocurre ya la enfermedad lleva varios años involucrando otros órganos y sistemas ${ }^{5}$. Si bien las manifestaciones iniciales pueden remontarse a los primeros años de vida e interrogando a los pacientes y a sus padres y madres salen a la luz quejas como dolores en miembros inferiores, sensaciones 'quemantes' en plantas, cólicos abdominales, intolerancia al calor o al ejercicio, anhidrosis, y a estas se van añadiendo las manifestaciones cutáneas conocidas como angioqueratomas ${ }^{1-4}$.

Entre las manifestaciones cardiovasculares no hay un síntoma trazador, premonitorio o patognomónico, y pueden verse anomalías sutiles, como bloqueos aurículo-ventriculares de primer grado o bloqueos de rama $^{8,9}$. Sin embargo, el signo de alarma es la hipertrofia ventricular izquierda en un paciente joven sin hipertensión ${ }^{3,8,9}$. Por supuesto, esto también puede presentarse en otras entidades clínicas como la miocardiopatía hipertrófica, pero si además se encuentran manifestaciones en otros sistemas, ya sea renales, dermatológicas y oftalmológicas (pérdida de agudeza visual) o auditivas, la sospecha debe elevarse para ordenar los estudios enzimáticos tendientes a hacer diagnósticos de enfermedad de Fabry ${ }^{6,7,10}$.

\section{Conclusión}

La invitación, en este caso, es a elevar el grado de sospecha diagnóstica cuando se encuentran alteraciones multisistémicas que van más allá de la competencia como cardiólogos, pero que puede nacer en una hipertrofia ventricular izquierda severa en un paciente sin etiología hipertensiva. 
Rev Colomb Cardiol. 2021;28(2)

\section{Financiamiento}

Los autores declaran que no existe financiamiento.

\section{Conflicto de intereses}

Los autores declaran no tener ningún conflicto de intereses.

\section{Agradecimientos}

Los auotres agradecen al equipo médico y de enfermería del servicio de consulta externa de nuestra institución que colaboraron en la recopilación de datos del paciente.

\section{Responsabilidades éticas}

Protección de personas y animales. Los autores declaran que para esta investigación no se han realizado experimentos en seres humanos ni en animales.

Confidencialidad de los datos. Los autores declaran que han seguido los protocolos de su centro de trabajo sobre la publicación de datos de pacientes.
Derecho a la privacidad y consentimiento informado. Los autores han obtenido el consentimiento informado de los pacientes y/o sujetos referidos en el artículo. Este documento obra en poder del autor de correspondencia.

\section{Bibliografía}

1. Zarate YA, Hopkin RJ. Fabry's disease. Lancet. 2008;372(9647):1427-35.

2. Putkko BN, Wen K, Thompson RB, Mullen J, Shanks M, Yogasundaram H, et al. Anderson-Fabry cardiomyopathy: prevalence, pathophysiology, diagnosis and treatment. Heart Fail Rev. 2015;20(2):179-91.

3. Martínez MJ, Meneses MS, Alasino M, Samper AA, Sarrió L. Enfermedad de Anderson Fabry: reporte de un caso. Arch Argent Dermatol. 2015;65(6):211-4.

4. Ramaswami U, Whybra C, Parini R, Mehta A, Pintos-Morell G, Sunder-Plassmann, G, et al. Clinical manifestations of Fabry in Children data from the Fabry Outcocme Survey. Acta Paediatr. 2006;95:86-92.

5. Pieroni M, Chimenti C, Ricci R, Sale P, Russo MA, Frustaci A. Early detection of Fabry cardiomyopathy by tissue Doppler imaging. Circulation. 2003;107(15):1978-84.

6. Nakao S, Takenata T, Maeda M, Kodama C, Tanaka A, Tahara M, et al An atypical variant of Fabry disease in men with left ventricular hypertrophy. N Engl J Med. 1995;333:228-93.

7. Varas C, Gómez G, Morales M, Molt F, Cabello JF, Alcántara A, et al Clinical guidelines: Chilean consensus in Fabry disease. Rev Chil Neuro-Psiquiat. 2012;50(3):191-20.

8. Michref A, Gullone N, Amarino H, Chamoles N. Manifestaciones cardiacas en once pacientes con enfermedad de Fabry. Revista Argentina de Cardiología. 2004;72(6):446-53.

9. Gómez MG, Varas C, Morales M, Bonacic F, Álvarez M, Rojas A. Cardiac Involvement in patients with Fabry's Disease. Rev Chil Cardiol. 2013;32 Vol 1: 28-33.

10. von Scheidt W, Eng CM, Fitzmaurice TF, Erdmann E, Hubner G, Eckhardt $\mathrm{G}$, et al. An atypical variant of Fabry's disease with manifestations confined to the myocardium. N Engl J Med. 199;324:395-9. 